[Aus dem Institut für Infectionskrankheiten in Berlin.] (Director: Geh. Med.-Rath Prof. Dr. R. Koch.)

\title{
Ueber die Agglutination der Pneumokokken und über die Theorieen der Agglutination.
}

\author{
Von
}

Dr. F. Neufeld,

Assistenten am Institut.

\section{Die Agglutination der Pneumokokken.}

Seit der Entdeckung des Agglutinationsphänomens sind bekanntlich überaus zahlreiche Untersuchungen auf diesem neu erschlossenen Gebiete angestellt worden: einerseits studirte man an einer grossen Anzahl von Bakterien die Bedingungen, unter denen die Agglutination eintritt, und die Art und Weise, wie sie verläuft; andererseits bemühte man sich, in das eigentliche Wesen dieses räthselhaften Vorganges einzudringen, seine tiefere Bedeutung und seinen Zusammenhang mit anderen, bereits länger bekannten Thatsachen der Immunitätslehre zu erkennen. Bei all' diesen Untersuchungen haben die Fränkel'schen Pneumokokken verhältnissmässig geringe Berücksichtigung gefunden. $\mathrm{Ja}$, wenn man, wie gewöhnlich, unter Agglutination einen Vorgang versteht, bei dem durch Zusatz von specifischem Serum die vorher getrennten Mikroorganismen einer Cultur in kurzer Zeit zu Haufen zusammengeballt werden, so ist eine Agglutination in diesem Sinne, wie sie den Gegenstand dieser Mittheilung bilder soll, bisher bei Pneumokokken überhaupt nicht beschrieben worden.

Rechnet man dagegen in einem weiteren Sinne des Wortes zur Agglutination auch die Erscheinung, dass ein Beaterium, wenn man es 
in einem specifischen Serum wachsen lässt, hier andere Wachsthumsform - nämlich ein Wachsthum in grossen Verbänden - annimmt, als in normalem Serum, dann ist ein derartiges Verhalten gerade beim Pneumococcus mit zuerst beobachtet worden, lange vor der Entdeckung der eigentlichen Agglutination, als deren Ausgangspunkt wohl allgemein die Veröffentlichungen von Gruber und Durham, sowie von. R. Pfeiffer und seinen Mitarbeitern angesehen werden (1896).

Bereits im Jahre 1891 hat nämlich Metschnik off ${ }^{1}$ die Beobachtung mitgetheilt, dass Pneumokokken, wenn sie in das Serum eines immunisirten Kaninchens eingesät wurden, nach 24 Stunden nach Art von Streptokokkeu zu langen, rielfach gewundenen Ketten auswuchsen, wäbrend sie im normalen Kaninchenserum stets Diplokokkenform zeigten. Diese Thatsache wurde von einer Reihe von Autoren, Mosny, Kruse und Pansini, Washbourne u. A. bestätigt; dieselben fanden neben der Kettenbildung oft mehr oder weniger deutliche Zeichen von Wachsthumshemmung und Degeneration und suchten einen Zusammenhang dieser Erscheinungen mit der Immunität festzustellen. Besançon und Griffon ${ }^{2}$ studirten diese Vorgänge weiterhin am Serum von Menschen, welche an Pneumonie oder auch an anderen, durch den Pneumococcus verursachten Krankheiten litten; sie fanden dieselben meist am Tage vor der Krisis deutlich ausgesprochen. Bei ihren recht zahlreichen Untersuchungen menseblichen und thierischen Blatserums berichten sie nur ron einem Kaninchen, dessen Blut ausnahmsweise so stark wirksam war, dass in demselben auch noch dann, wenn es bis 1:50 verdünnt wurde, das charakteristische Wachsthum nach 24 Stunden eintrat. Thre übrigen Nlittheilungen beziehen sich ebenso wie die der anderen Autoren nur auf das Wachsthum in reinem Serum.

Somit fehlen also bei den bisherigen Beobachtungen zwei Kriterien, die wir von den Versuchen an anderen Bakterien her als wesentliche Merkmale der Agglutination anzusehen gewohnt sind: einmal, dass die Reaction auch in verdünntem Serum stattfindet, zweitens und hauptsäehlich aber, dass sie beim Zusammenbringen von Serum und Cultur sogleich oder in kurzer Zeit auftritt. Diese Phänomene nun, welche bei Zusatz von agglutinirendem Serum in wechselndem Verhältniss zu einer Pneumokokkencultur alsbald auftreten, sollen im Folgenden vorzugsweise beschrieben werden: denn nur an ihnen lässt sich zeigen, wie die Pneumokokken in wesentlichen Punkten ein ganz abweichendes Verhalten von anderen agglutinirten Bakterien erkennen lassen, und wie sie daher geeignet sind, auf einige

1 Annales de l'Institut Pasteur. T. V. p. 474.

2 Ebenda. 1900. 
allgemeine Fragen betreffs der Agglutination neues Licht zu werfen. Und gerade in diesen Besonderheiten der Pneumokokkenagglutination und in den Rückschlüssen, welche sich daraus auf das Wesen der Agglutination im Allgemeinen ergeben, scheint mir das Hauptinteresse derselben zu bestehen; eine praktische Wichtigkeit dagegen, wie der Typhus- und CholeraAgglutination, dürfte ihr meiner Ansicht nach nur selten zukommen.

Dass die Thatsachen dieser Agglutination den bisherigen Untersuchern entgangen sind, lässt sich daraus erklären, dass die Gewinnung eines derartig agglutinirenden Serums keineswegs so leicht gelingt, wie bei Cholera oder Typhus: auch bei hoch immunisirten Thieren ist ein in unserem Sinne deutlich agglutinirendes Serum nicht etwa regelmässig, sondern nur unter besonderen Bedingungen zu erwarten, während sich ein immunisirendes Serum viel leichter herstellen lässt. Eher wäre es zu verwundern, dass bei dem Eifer, mit dem in so vielen Kliniken heutzutage die Agglutinationsvorgänge studirt werden, noch nicht über derartige Beobachtungen an dem Blute von Pneumonie-Reconvalescenten berichtet worden ist; denn solche Patienten liefern 2war durchaus nicht regelmässig, aber anscheinend doch nicht ganz selten ein kräftig agglutinirendes Serum. Doch bevor ich auf die Bedingungen $z \mathrm{u}$ sprechen komme, unter denen ein solches Serum auftritt, will ich die Wirkungen desselben beschreiben.

Auf gewisse Bakterien übt bekanntlich auch das normale Serum in reinem oder verdünntem Zustande mehr oder weniger stark agglutinirende Wirkung aus, eine Thatsache, deren ungenügende Berücksichtigung Anfangs zu manchen Fehlschlüssen Anlass gegeben hat. Beim Arbeiten mit den Diplokokken der Pneumonie sind Irrthūmer nach dieser Richtung hin nicht zu befürchten; denn wenigstens das Serum von normalen Menschen und Kaninchen - auf. welche Blutarten allein sich die folgenden Mittheilungen beziehen - brachte in einer grossen Anzahl von untersuchten Proben auch in unverdünntem Zustande niemals irgend welche Agglutination oder sonstige Formveränderung an eingebrachten Pneumokokken zu Stande.

Die Veränderungen nun, welche die Fränkel'schen Diplokokken bei Zusatz eines agglutinirenden Blutes erfahren, sind ganz verschieden, je nach der Concentration, in welcher das Blut einwirkt. Bei diesen Untersuchungen kamen in der Regel Bouillonculturen unseres Mikroorganismus zur Verwendung, und, wo nichts anderes bemerkt ist, beziehen sich alle folgenden Angaben auf eine 24- bis 48 stündige Botilloncultur, welche in wechselndem Verhältniss auf eine kleine, in einem Reagensrohr befindliche Quantität des Serums aufgegossen wurde, so dass sofort eine genügende Vermischung eintritt. 
Mischt man nun gleiche Theile von agglutinirendem Serum und Pneumokokkenbouilloncultur, sei es im Reagensglase, sei es durch inniges Verreiben, je einer Platinöse Serum und Cultur auf einem Deckglase, so beobachtet man im hängenden Tropfen deutliche Quellungserscheinungen, die bei einem kräftig wirksamen Serum sofort oder nach einigen Minuten auftreten. Die einzelnen Kokken schwellen bis zum Doppelten und Dreifachen ihrer Grösse an, sie platten sich dabei an ihren Berührungsstellen, die sonst zugespitzt sind, gegen einander $a b$ und die ganzen Contouren werden undeutlicher und verschwimmend. Bisweilen lässt sich deutlich erkennen, dass an diesem Quellungsprocess hauptsächlich die ausseren Schichten der Bakterienzelle betheiligt sind: sie wandeln sich in eine homogene, glasige Masse um, während in der Mitte des Coccus ein dunklerer, runder Kern zu sehen ist. Diese Vorgānge erwecken zunächst den Eindruck, als ob es sich um eine hochgradige Degeneration und um den Beginn der Auflösung des Bacteriums durch das Serum handelte. Dieser Eindruck wird bestärkt durch die Thatsache, dass derartig gequollene Pneumokokken ihre Färbbarkeit verloren haben. Sie nehmen, in der gewöhnlichen Weise getrocknet und fixirt, meist gar keinen Farbstoff an; setzt man $\mathrm{zu}$ dem flüssigen Tropfen vorsichtig eine Farblösung zu, so gelingt es höchstens, die beschriebenen dunkelen Körnchen in der Mitte der eigentlich gequollenen Massen zu färben, wāhrend diese selbst ungefärbt bleiben.

Trotzdem man also auf den ersten Blick geneigt sein könnte, in diesen Vorgängen die beginnende Vernichtung des Bacteriums dureh das specifische Serum und die Ursache der immunisirenden Wirkung des letzteren zu sehen, so mahnen doch weitere Beobachtungen $\mathrm{zu}$ einem vorsichtigeren Urtheil. Zunächst handelt es sich zweifellos nicht um ein Phänomen, das mit dem Leben und Absterben der Bakterienzelle in nothwendigem Zusammenhange steht; denn dasselbe lässt sich in ganz derselben Weise beobachten an abgetödteten Pneumokokken, ja selbst an solchen, die Stunden lang im Dampftopf gekocht sind. Andererseits führen auch diese Vorgänge in der Regel weder zur völligen Auflösung - eine solche habe ich nie mit Sicherheit beobachtet, und lasse es dahingestellt, ob sie vorkommt - noch auch zur Abtödtung des Bacteriums: denn auch aus hängenden Tropfen, in denen alle Ketten die stärksten Quellungserscheinungen boten, liess sich durch Züchtung eine reichliche und völlig normale Cultur gewinnen. Schliesslich kann ich der beschriebenen Erscheinung schon deshalb keine directe Beziehung zu Immunitätsvorgängen zuschreiben, weil ich oft kräftig immunisirende Sera in Händen gehabt habe, die keine Spur davon zeigten.

Die erwähnten Veränderungen an den Pneumokokkenketten nehmen 
im weiteren Verlaufe noch zu; die Grenzen der einzelnen Kokken gegen einander werden undeutlicher, so dass eine so gequollene Kette ein fast homogenes, schlauchförmiges Gebilde darstellt; nach Verlauf von einer oder mehreren Stunden kann eine auf diese Weise veränderte Cultur kaum noch eine Aehnlichkeit mit ihren ursprünglichen Formen darbieten. Alle diese Veränderungen betreffen stets in gleichmässiger Weise sämmtliche Glieder der Pneumokokkenketten; sie sind mit den oft recht beträchtlichen kugeligen Auftreibungen, die man so häufig in ungünstigen Nährböden an einżelnen Kokken sieht, in keiner Weise zu verwechseln.

Sehr viel langsamer und zunächst nur andeutungsweise tritt bei der Mischung von Serum und Cultur zu gleichen Theilen, insbesondere dann, wenn diese Mischung auf dem Deckglase vorgenommen wird, ein zweites Phänomen auf, nämlich eine Anordnung der Mikroorganismen zu Haufen. Man sieht Anfangs neben der Mehrzahl von einzeln liegenden, stark gequollenen Ketten, andere zu kleinen Häufchen oder Knäueln zusammentreten. Erst ganz allmählich nimmt diese Haufenbildung zu und vollendet sich im Verlaufe von Stunden; alsdann ist die ganze Menge der Kokken zu einigen grossen, makroskopisch sichtbaren Klumpen zusammengeballt, deren einzelne Bestandtheile durch starke Quellung mehr oder weniger unkenntlich geworden sind.

Ganz anders gestalten sich die Vorgänge, wenn das agglutinirende Serum in schwächerer Concentration mit der Cultur gemischt wird, also etwa im Verbältniss von 1 Theil Serum zu 4 bis 8 Theilen Pneumokokkenbouilloncultur. Dann tritt eine vollkommene Agglutination ein; jedoch fast nie in der Weise, wie z. B. bei Cholera- oder Typhusbacillen, wo die Mikroorganismen zu regellosen Haufen zusammengeballt werden, sondern es setzen sich in durchaus regelmässiger Anordnung die einzelnen Diplokokken bezw. kurzen Ketten in ihrer Längsrichtung an einander und bilden Ketten bis zu vielen Hunderten von Gliedern, die sich vielfach in einander verschlingen und lockere, zierlich gewundene Knäuel bilden. Diese werden allmäblich immer grösser und mit blossem Auge sichtbar, während die dazwischen befindliche Flüssigkeit sich klärt. Anfangs sind diese Knäuel meist ganz locker gefügt, so dass man die endlose Kette, aus der ein einzelner Haufen besteht, ganz genau in allen ihren Verschlingungen verfolgen kann; alsdann ähnelt das Bild ausserordentlich der bei Coli, Typhus u.s.w. beobachteten "Fadenreaction". Der wichtige Unterschied ist jedoch der, dass bei der Fadenreaction der genannten Mikroorganismen die langen Ketten nur beim Wachsthum der Bakterien im (verdünnten) Serum entstehen, während in unserem Falle die fertig gebildeten Bakterien sogleich unter dem Einfluss des Serums sich zu solchen regelmässigen Ketten vereinigen. Wenn sich bei längerem Stehen die.Ketten fester an 
einander schliessen, so gewinnen sie grosse Aehnlichkeit mit Streptococcus longus-Culturen.

Bei gut agglutinirenden Serumproben fand ich in den angegebenen Verdünnungen nach Verlauf von $1 / 4$ bis $1 / 2$ Stunde bereits Knäuel ron so grosser Ausdehnung, dass sie sich durch mehrere Gesichtsfelder der Oelimmersion erstreckten und auch mit blossem Auge, sowie bei schwacher Vergrösserung wahrnehmbar waren.

Bei dieser Knäuelbildung, wie sie ungefähr in den angegebenen Verdünnungen stattfindet, ist eine Vergrösserung und FormFeränderung der Pneumokokken durch Quellung noch deutlich wahrnehmbar, sie ist aber viel schwächer als bei der Finwirkung des unverdünnten Serums auf die Cultur, und sie tritt um so mehr zurück, in je geringerer Concentration man das Serum einwirken lässt. Gleichzeitig mit der Abnahme der Quellung nimmt die Färbbarkeit der Kokken wieder zu, so dass man ron den in stärkeren Serumverdünnungen entstandenen Knäueln leidlich gut gefärbte Präparate erhalten kann.

Die Stärke der Concentration eines Serums, bei welcher die beschriebenen Erscheinungen auftreten, sowie die Schnelligkeit, mit der sie sich entwickeln, variirte natürlich bei den verschiedenen von mir geprüften Sera. Als. agglutinirendes Serum ron mittlerer Stärke möchte ich ein solches bezeichnen, in welchem die Quellung der Diplokokken bei Mischung ron gleichen Quanten von Serum und Cultur sofort beginnt, deutliche Bildung grösserer Knäuel bei einem Verhältniss von 1:4 bis $1: 8$ nach einigen Minuten bis zu $1 / 2$ Stunde erfolgt, während bei Verdünnungen über 1:10 oder 1:15 nur unvollkommene Haufenbildung sich zeigt. Die stärksten Serumarten, wie ich sie sowobl von immunisirten Kaninchen wie auch von Pneumonie-Reconvalescenten erhielt, agglutinirten noch die 50- bis 60 fache Menge Bouilloncultur in typischer Weise. Man darf diese Zahlen, glaube ich, nicht ohne Weiteres in Parallele stellen mit den Agglutinationswerthen z. B. von Cholera- oder Typhusbacillen, sondern muss berücksichtigen, dass diese letzteren oft von normalem Serum in erheblichem Grade beeinflusst werden, was, wie schon erwähnt, bei den Pneumokokken nicht der Fall ist, wenigstens niemals bei Menschen- und Kaninchenserum, auf die sich die mitgetheilten Beobachtungen zunächst ausschliesslich beziehen. Dagegen will ich hier eine Thatsache nicht unerwähnt lassen, die mir von. Interesse erscheint, dass nämlich das normale Rinderblut bäufig an Pneumokokken sowohl deutliche Quellung als anch Häufchenbildung hervorruft.

Es wurde bereits erwähnt, dass die Veränderungen, welche die Pneumokokken unter dem Einflusse eines agglutinirenden Serums erfahren, sich 
ebenso gut an abgetödteten als an lebenden Culturen beobachten lassen. Dass die Agglutination überhaupt mit der Vitalität der Bakterien nichts $\mathrm{zu}$ thun hat, ist bereits lange, zuerst von Bordet, constatirt worden; jedoch verhalten sich die einzelnen Bakterienarten in dieser Hinsicht recht verschieden. So agglutiniren z. B. Typhusbacillen, auch wenn sie vorsichtig durch Wärme abgetödtet werden, schon schlechter als lebend, und nach einmaligem Aufkochen über der Flamme ist ihre Agglutinationsfähigkeit erheblich herabgesetzt. Ganz anders bei den Pneumokokken. Ich habe dieselben bis zu 3 Stunden im Dampftopfe gekocht, ohne dass ihre Agglutinations- und Quellungsfähigkeit eine deutliche Verminderung erfahren hätte. Es wäre also der Bestandtheil der Bakterienzelle, auf welchem die Agglutinationsfähigkeit derselben beruht, die ,agglutinirbare Substanz" gerade des Pneumococcus von.einer ganz ausserordentlichen Widerstandsfähigkeit gegen Hitze. Dagegen wird der chemische Körper, welcher im Serum als der Träger der specifischen Wirkung angenommen werden muss, das „Agglutinin“, bereits bei einer unter $100^{\circ}$ gelegenen Temperatur zerstört. Demuach ist gerade bei den Pneumokokken die Differenz in dem Verhalten dieser beiden, bei der Agglutination in Wechselwirkung tretenden Körper gegen Wärme eine besonders grosse und es liegt daher nahe, zu untersuchen, wie sich die bereits agglutinirten Pneumokokken beim Erwärmen verhalten. Erhitzt man ein Gemisch von Serum und Bouilloncultur, in welchem die Agglutination bereits eingetreten ist, bis nahe zum Kochen, so sieht man sowohl die Quellung als auch die Knäuelbildung plötzlich vollständig verschwinden, so dass man wieder dieselben kleinen Diplokokken bezw. die starren, kurzen Ketten vor sich hat, von denen man ausgegangen ist. Dieselben lassen sich durch Zusatz von frischem Serum wiederum zur Agglutination bringen; ihre agglutinirbare Substanz hat also keinen Schaden genommen. Der gleichzeitig beim Erhitzen auftretende Serumniederschlag hat mit dem Vorgange nichts zu thun; denn wenn man die agglutinirten Kokken abcentrifugirt, in Kochsalzlösung aufschwemmt und nun erhitzt, so tritt ebenfalls eine Lösung der Agglutinationshaufen und Wiederherstellung des status quo ante auf, ohne dass ein Niederschlag erfolgt.

Wie erwähnt, bildet sich beim Erhitzen auch die Quellung der Bakterien völlig zurück; dieselbe stellt also einen durchaus reparabeln Zustand der Bakterienzelle dar; wird das in die Zelle aufgenommene Agglutinin zerstört, so nimmt das Bacterium seine ursprüngliche Form wieder an. Und gleichzeitig damit kehrt auch die Färbbarkeit zurück, die bei den gequollenen Diplokokken mehr oder weniger vollständig geschwunden war.

Als ich die Wirkung eines agglutinirenden Serums auf versehiedene Pneumokokkenstämme untersuchte, fand ich auch in dieser Beziehung 
unerwartete Abweichungen von den bei der Agglutination anderer Bakterien bekannten Verhältuissen.

Bei Typhus- und Cholerabacillen sehen wir, dass ein kräftig wirksames Serum sämmtliche Stämme derselben Art zur Agglutination bringt, wenn sich auch quantitative Cnterschiede dabei herausgestellt haben, bisweilen nicht unerheblicher Art, indem gewisse Culturen zur Agglutination einer längeren Zeit bezw. einer stärkeren Concentration bedürfen, als andere. Meist stellte sich in solchen Fällen heraus, dass die weniger virulenten Stämme besser agglutinirten, als die virulenteren (Pfeiffer und Kolle). Ganz andere Verbältnisse ergaben sich bei dem Bacterium coli. Es zeigte sich, dass ein mit einem bestimmten Bacterium coli hergestelltes Serum auf eine Anzahl Colistämme gar keine Agglutinationswirkung hatte, auf einige andere eine schwache, und nur auf den eigenen Stamm und eine geringe Anzahl anderer, ihm offenbar besonders nahestehender Stämme seine volle Wirkung äusserte.

Ein noch anderes Verhalten fand ich nun bei den Pneumokokken. So lange ich Stämme, die auf der Höhe ihrer Virulenz erhalten waren, untersuchte, fand ich keinen Untersehied in der Agglutinirbarkeit: ein mit dem Pneumococcus A gewonnenes Serum agglutinirte ebenso gut den Pneumococcus B oder C, und auch das Blut von Pneumonie-Reconvalescenten zeigte fremden Diplokokken gegenüber dieselbe Wirksamkeit als den aus dem Sputum des betreffenden Kranken isolirten. Dagegen wurde ein ron Anfang an (für Kauinchen) ganz unvirulenter Stamm von Kaninchenserum gar nicht agglutinirt, und ebenso beobachtete ich mehrmals, dass ein Stamm, der vorher gut agglutinirt worden war, später, als er im Laufe der Fortzüchtung seine Virulenz völlig eingebüsst hatte, gar keine Agglutination mehr zeigte. Es fand also bier gerade das umgekehrte Verhältniss zwischen Virulenz und Agglutinirbarkeit statt, wie wir es von den Cholera- und Typhusbacillen her kennen. Meine Beobachtungen sind vielleicht nicht zahlreich genug, um das oben beschriebene Verhalten als ein ganz constantes bei der Pneumokokkenagglutination anzusehen, aber sie lehren, dass für jede Bakterienart erst auf's Neue der Kreis bestimmt werden muss, innerhalb dessen sich die Agglutinationswirkung des mit einem Bacterium hergesteliten Serums äussert. Für die Pneumokokken ergiebt sich daraus die Unmöglichkeit, die Agglutinationsfāhigkeit ohne weiteres als Artmerkmal aufzustellen.

Schliesslich sei noch eine Eigenthümlichkeit des agglutinirenden Pneumokokkenserums erwähnt, welche das Arbeiten mit demselben recht erschwert; nämlieh die schnelle Abnahme seiner Wirksamkeit. Im Eisschrank aufbewahrtes Serum blieb nur etwa 8 bis 14 Tage unverändert, dann trat eine so schnelle Verminderung des Agglutinationsvermögens ein, 
dass nach wenigen Wochen nichts mehr davon nachzuweisen war. Dieselbe Beobachtung wurde übrigens anch an unconservirtem Serum gemacht, so dass man nicht allein dem Carbolzusatz Schuld geben kann.

\section{Die Theorieen der Agglutination.}

Aus den mitgetheilten Thatsachen geht hervor, dass die Agglutination bei den Pneumokokken unter wesentlich anderen Formen verläuft, als bei anderen Bakterien, und es erscheint daher von Interesse, zu sehen, in wieweit die für die Agglutination dieser letzteren aufgestellten Theorieen in den Vorgängen der Pneumokokkenagglutination eine Stütze finden. Ich möchte daher hier einige allgemeine Betrachtungen über das Wesen der Agglutination überhaupt anschliessen, die sich theils auf die mitgetheilten Beobachtungen an Pneumokokken, theils auf solehe an anderen Bakterien gründen.

Ueber das Wesen des Agglutinationsphänomens sind bekanntlich schon seit längerer Zeit verschiedene Hypothesen aufgestellt worden, ohne dass, wie es scheint, eine derselben za allgemeiner Anerkennung gelangt wäre. Der erste Erklärungsversuch rührt von Gruber her: danach sollten unter dem Einfluss des Serums die äusseren Sehichten der Bakterienzelle aufquellen und klebrig werden, und so dureh Aneinanderkleben der Bakterien die Haufen entstehen. Nun lässt sich bei der Agglutination der übrigen Bakterien ron einer solchen Quellung nichts nachweisen ${ }^{1}$, und die Gruber'sche Annahme blieb daher rein hypothetisch. Bei den Pneumokokken dagegen haben wir eine ausgesprochene Quellung des Bakterienleibes kennen gelernt, anscheinend hauptsächlich die äusseren Schichten betreffend, also ganz entsprechend der Gruber'schen Annahme.

Es lässt sich jedoch nicht erkennen, dass mit dieser Quellung ein Klebrigwerden der Bakterien verbunden wäre. Wenn man sich aber wirklich die Oberfläche der Bakterien als klebrig vorstellen wollte, so müsste man für die Preumokokken noch die weitere Annahme machen, dass diese klebrige Substanz nur an den beiden Enden des Diplococeus zur Ausscheidung käme. Diese Vorstellung hätte schliesslich keine besondere Schwierigkeit; aber dann bliebe immer noch die Kraft zu erklären,

1 Dagegen sind Quellungserscheinungen in agglutinirendem Serum bei Oidium albicans von Roger (Revue gén. des Sciences, 1896) beschrieben worden. Gegenüber dem von Bordet erhobenen Einwande, dass diese Quellung vielleicht nicht eine Begleiterscheinung der Agglatination, sondern der Bakteriolyse sei, will ich bemerken, dass bei den Pneumokokken die Quellung auch in complementfreiem Serum stattfindet, dagegen in frischem, gut immunisirendem, aber nicht agglutinirendem Serum fehlt. 
welche eine Annäherung der unbeweglichen Bakterien aneinander bewirkt, denn sonst würden doch die supponirten klebrigen Stellen gar nicht in Berührung gerathen. Dieselbe Schwierigkeit würde sich ergeben, wenn man die Agglutination geisseltragender, aber abgetödteter Bakterien allein durch ein Klebrigwerden ihrer Oberfläche erklären wollte. So tritt z. B. bei Typhusbacillen, die bei $58^{\circ}$ abgetôdtet und also auch ihrer Beweglichkeit beraubt sind, bei Zusatz genügender Serummengen (es ist nur wenig mehr als bei lebenden Bacillen erforderlich) sofort, and ohne dass ein Schütteln nöthig wäre, starke Haufenbildung ein. Auch hier muss man zunächst eine besondere Kraft annehmen, welche die getrennten Mikroorganismen einander nahe bringt. Dieselbe Kraft würde dann aber auch genügen, um sie in Haufen zusammen zu ballen, und die Annahme der Entstehung einer klebrigen Substanz erscheint überflüssig.

Welches aber sind nun die Kräfte, welche eine plötzliche Annäherung. der Bakterien an einander und eine Bildung von Haufen bewirken? Auf diese Frage glauben eine Anzahl von Autoren eine genügende Antwort zu haben: es sind Niederschläge, welche durch das agglutinirende Serum in der die Balkterien umgebenden Flüssigkeit entstehen und diese mit sich reissen; die Bakterien selbst spielen dabei eine völlig passive Rolle, sie werden ,wie in einem Netze gefangen". Diese Hypothese stützt sich auf die von Kraus ${ }^{1}$ gefundene Thatsache, dass in den Filtraten älterer Bouillonculturen von Typhus-, Cholera- und Pestbacillen bei Zusatz von kräftig agglutinirendem Serum specifische Niederschläge auftreten. Zuerst und am bestimmtesten bat Paltauf ${ }^{2}$ die Ansicht ausgesprochen, dass diese Niederschläge die directe Trsache der Agglutination seien, und „dass die agglutinirten Mikroorganismen durch entstehende Niedersehläge mitgerissen und auf diese Weise agglutinirt werden". Man sieht sogleich, dass sich auf diese Weise die Agglutination der Pneumokokken nicht erklären lassen würde, da es sich dabei nicht um unregelmässig zusammengeballte Bakterienbaufen, sondern um typisch angeordnete Ketten und Knärtel handelt, deren Entstehung man sich durch einen Zug von aussen her bei ganz passivem Verbalten der Nikroorganismen kaum vorstellen kann. Dasselbe würde für die Agglutination der Trypanosomen gelten, welche nach den jüngst veröffentlichten Untersuchungen von Laveran Mesnil ${ }^{3}$ in ganz typischer Weise erfolgt, indem die Organismen sich stets mit demselben Körperende an einander heften, so dass sich zierliche Rosetten bilden.

1 Wiener klin. Wochenschrift. 1897.

Ebenda.

${ }^{3}$ Annales de l'Institut Pasteur. 1901. 
Alle diese Erscheinungen stimmen mit der Annahme von Niederschlägen, welche in der Flüssigkeit entstehen und die darin suspendirten corpusculären Elemente mit sich reissen, nicht überein.

Aber schon die weiteren Untersuchungen von Kraus, sowie von Nicolle ${ }^{1}$ über die Niederschläge in den Culturfiltraten liessen die Bedeutung derselben in einem etwas anderen Lichte erscheinen. Einmal zeigte sich eine starke Incongruenz zwischen den Bedingungen, unter denen die Niederschläge einerseits, die Agglutination andererseits auftreten, und in dem zeitlichen Verlauf beider Phänomene. Die Niederschläge in den klaren Filtraten entstehen nur bei viel concentrirterer Einwirkung des Serums, als zur Agglutination erforderlich, und auch dann brauchen sie zu ihrer Ausbildung viel längere Zeit, meist mehrere Stunden. Ferner stellte sich heraus, dass die Substanz, welche in den Filtraten präcipitirt wird, nicht von Anfang an in der Umgebung der Bakterien existirt, sondern erst allmählich, offenbar beim Zugrundegehen der Bakterienkörper aus diesen diffundirt, also dem Bakterienleibe selbst entstammt.

Hiernach würden die Kraus'schen Niederschläge gewissermaassen als das Aequiralent der Agglutination erscheinen; je nachdem sich die agglutinirbare Substanz frei in der Flüssigkeit oder aber innerhalb des Bacteriums befindet, würde das eine oder das andere Phänomen auftreten. Dabei ist zunächst immer angenommen worden, dass es ein und derselbe Bestandtheil des Serums ist, welcher beide Vorgänge auslöst. Diese Annahme wird jedoch in Frage gestellt durch neuere Untersuchungen, welche Radzievsky" über die Agglutination und "Präcipitation" (d. h. die Niedersehlagsbildung im sterilen Culturfiltrat) bei Bacterium coli, Bail ${ }^{3}$ analog beim Typhusbacillus angestellt hat. Beide Autoren fanden, dass ein Serum, nachdem es im Filtrat der betreffenden Bakteriencultur den specifiischen Niederschlag erzeugt hat, dadurch seine Agglutinationsfähigkeit nicht eingebüsst, ja nicht einmal eine Verminderung derselben erfahren habe; sie ziehen daraus den Schluss, dass das Präcipitin des Serums von dem Agglutinin verschieden sei. Darnach würden also die beiden Phänomene noch weiter von einander zu trennen sein, als es nach den bisherigen Untersuchungen den Anschein hatte. Ich will an dieser Stelle auf diese, wie mir scheint, die Frage noch nicht erschöpfenden Untersuchungen nicht eingehen, da sie auf die hier zu erörternden Theorieen über das Zustandekommen der Agglutination von keinem directen Einflusse sind.

1 Annales de l’Institut Pasteur. 1898.

Diese Zeitschrift. Bd. XXXIV.

s Prager med. Wochenschrift. 1901. 
Als wesentlich dafür erscheint mir nur der Nachweis, dass die Substanz, welche in den Culturfiltraten präcipitirt wird, in der That zunächst dem Bakterienkörper adhärirt und erst secundär aus demselben an die Nāhrflüssigkeit abgegeben wird, während sie nach der Paltauf'schen Theorie doch von Anfang an ausserhalb der Bakterien vorhanden sein müsste, um dieselben beim Präcipitiren mitreissen zu können. Nur in diesem Falle würde der Vergleich der Agglutination mit jener nicht specifischen Haufenbildung völlig stimmen, die in Bouillon aufgesebwemmte Mikroorganismen oder auch anorganische Partikel wie Tusche oder Talk nach Zusatz z. B. von Alkohol zeigen (Nicolle, Kraus). In diesem Falle befindet sich die Substanz, welche mit dem Alkohol einen Niederschlag bildet, in der That nicht innerhalb, sondern völlig ausserhalb der corpusculären Elemente und kann diese daher wirklich mit sich reissen. Dementsprechend bleibt auch jede Haufenbildung aus, wenn dieselben Partikel in einem anderen Medium, z. B. Kochsalzlösung, suspendirt sind, in welchem Alkohol keinen Niederschlag erzeugt, während Bakterien natürlich in Kochsalzlösung ebensogut agglutinirt werden wie in Bouillon.

Dieser Nachweis nun, dass die präcipitirbare Substanz sich zunächst ausschliesslich in dem Bakterienkörper befindet, lässt sich bei den Pneumokokken besonders gut führen, da wir bisher nur bei ihnen im Stande sind, die Körpersubstanz des Bacteriums schnell, und anscheinend ohne dass dabei die specifischen Bestandtheile alterirt werden, in eine vollkommene Lösung überzuführen. Dies geschieht, wie ich in einer früheren Arbeit mitgetheilt habe ${ }^{1}$, durch die Einwirkung normaler Galle auf eine frische Pneumokokkencultur. Meist genügt ein Tropfen normaler Kaninchengalle, um einen oder einige Cubikcentimeter Pneumokokkenbouilloncultur in kurzer Zeit in eine klare Lösung zu verwandeln. Setzte ich nun zu dieser Lösung z. B. im Verhältniss von 1:2, 1:4 und 1:8 ein Serum zu, das lebende Pneumokokken bis etwa 1:15 agglutinirte, so traten nach einiger Zeit eigenartige Niederschlagsbildungen auf. Dieselben waren ungefähr nach $1 / 4$ Stunde mikroskopisch wahrnehmbar und erschienen im hängenden Tropfen als schwach lichtbrechende, hyalinähnliche. Massen von kugeliger oder länglicher Form und der Grösse eines Blutkörperchens und darüber. Sie wurden allmählich grösser und ballten sich zu makroskopisch sichtbaren dicken Klumpen zusammen. Diese eigenthümlichen Bildungen traten nur auf Zusatz von agglutinirendem, nicht von normalem Serum auf und sind daher als besonders geformte Niederschläge der gelösten Pneumokokkensubstanz aufzufassen.

${ }^{1}$ Deber eine specifische bakteriolytische Wirkung der Galle. Diese Zeitschrift. Bò. XXXIV. 
Es scheint also ein allgemeines Gesetz zu sein, dass ein Serum, welches eine Bakterienart zu specifischer Agglutination bringt, in einer Flüssigkeit, in der genügende Mengen von Körpersubstanz derselben Bakterien in Lösung enthalten sind, einen Niederschlag hervorruft. Hierbei mag es dahingestellt bleiben, ob bei beiden Vorgängen ein und derselbe Stoff wirksam ist, oder ob es sich um zwei verschiedene Stoffe handelt, die aber in der Regel im Verlaufe der Immunisirung gleichzeitig auftreten. Jedenfalls entstehen bei Behandlung von Thieren mit den Körpersubstanzen von Bakterien im Blute der Thiere Stoffe, welche in einer Lösung jener Bakterienbestandtheile Niederschläge erzeugen. Diese Thatsache können wir heute als Theilerscheinung eines viel umfassenderen Gesetzes ansehen: wissen wir doch von einer grossen Anzahl thierischer und planzlicher Eiweissstoffe bezw. den Eiweissstoffen nahestehenden Körpern, dass sich mit denselben bei Thieren ein Serum erzeugen lässt, welches mit dem betreffenden Eiweissstoffe, und nur mit diesem, einen Niederschlag bildet. Solche Eiweissstoffe, welche einen specifischen Antikörper im Thierorganismus zu erzeugen nnd mit diesem eine Niederschlagsbildung herrorzurufen im Stande sind, kennen wir im menschlichen und thierischen Blutserum, in der Milch verschiedener Thierarten, im Ricin u.s.w. Der grossen Reihe dieser Stoffe können wir nunmehr solche zur Seite stellen, welche in den agglutinationsfähigen Bakterien enthalten sind, und aus diesen allmählich in die umgebende Flüssigkeit diffundiren, bei den Pneumokokken aber ausserdem durch eine specifische Einwirkung der Galle schnell in Lösung übergeführt werden können.

Alle diese Thatsachen erleichtern uns ausserordentlich das Verständniss dessen, was man nach dem Vorgange von Bordet als die erste Phase des Agglutinationsphänomens bezeichnet hat, und was man auch wohl die rein chemische Phase des Vorganges nennen könnte. Wir bönnen darnach annehmen, dass innerhalb des Bacteriums zwischen dem Agglutinin des Stanmes und der agglutinirbaren Substanz des Bacteriums eine ähnliche specifische Bindung und Umsetzung entsteht, wie zwischen den vorhin angeführten Stoffen und ihren zugehörigen Antistoffen. Für die zweite Phase der Agglutination dagegen, d. h. für die eigentliche Haufenbildung, welche als Folge dieser Umsetzungen stattfindet, kommen nach der Annahme Bordet's, dem ich mich hierin durchaus anschliesse, hauptsächlich physikalische Vorgänge in Betracht, auf deren Natur wir wohl am ehesten uns den physikalischen Verhältnissen, welche eine normale Bakteriencultur in einem flüssigen Nährboden darbietet, Rückschlüsse ziehen können.

Ich möchte also annehmen, dass unter dem Einflusse des Agglutinins in den oberfächlichen Schichten der Bakterienzelle eigenthümliche Ver- 
änderungen, etwa Gerinnungsvorgänge an sonst flüssigen Zellbestandtheilen auftreten, die nur bei den Pneumokokken mit einer sichtbaren Quellung verbunden sind, für gewöhnlich jedoch keine wahrnehmbare Formveränderung, dafür aber eine tiefgreifende Aenderung derjenigen physikalischen Eigenschaften hervorrufen, auf denen die Anordnung der Bakterien innerhalb ihres flüssigen Mediums und der Gleichgewichtszustand beruhen, in dem sich dieselben unter einander und mit der umgebenden Flüssigkeit befinden.

Dass sich in der That Bakterien innerhalb eines flüssigen Mediums nur in ganz bestimmter Anordnung in diesem "Gleichgewichtszustande" befinden, lässt sich aus der typischen Lagerung, welche wir in flüssigen Culturen unbeweglicher Bakterien zu sehen gewohnt sind, entnehmen. Man denke an die Gruppirung eines unbeweglichen B. coli in der Bouilloncultur im Vergleich mit Diphtherie- oder Nilzbrandbacillen, an das Wachsthum von Streptococcus longus verglichen mit Streptococcus brevis und dem Pneumococcus. Die Bildung der langen Ketten beim Streptococcus longus lässt sich z. B. nicht allein dadurch erklären, dass bei fortgesetzten Längstheilung die neugebildeten Glieder an den alten haften bleiben: denn sprengt man dieselben durch kräftiges Schütteln, wobei sich die vorher völlig klare Zwischenflüssigkeit trübt, so sieht man, dass sich nach kürzerer oder lāngerer Zeit der alte Zustand von selbst wieder berstellt; es müssen also besondere Kräfte thätig sein, die Bakterien wieder der ursprünglichen Gruppirung zuzuführen. Uebrigens ist auch das Aussehen einer Streptokokkencultur keineswegs allein durch die Länge der Ketten bestimmt, sondern auch durch deren ganz charakteristische Wendungen; man kann unter gewissen Bedingungen z. B. auch bei Pneumokokken Ketten von 20 bis 30 Gliedern beobachten, die sich durch ihre starre Anordnung von mittellangen Streptokokken mit gleicher Gliederzahl absolut unterscheiden. Andererseits zeigen auch die Streptokokken unter einander, wie bekannt, ganz ausserordentliche Differenzen in der Anordnung ihrer Bouillonculturen, welche jedoch für eine bestimmte Streptokokkenart innerhalb einund derselben Nährflüssigkeit durchaus gesetzmässig sind. Es variiren die Länge der Ketten, die Art der Windungen, die Grösse der Convolute; sehr rerschieden ist auch die Festigkeit, mit der die einzelnen Ketten zu Knāueln an einander haften: bei vielen Culturen gelingt es schon durch leichtes Sehütteln die Knänel zu sprengen, bei anderen überhaupt nicht. Ferner können bei ungefähr gleicher Grösse die Convolute innerhalb der Bouillon ganz verschieden vertheilt sein: sie können sämmtlich an Boden liegen oder sich hauptsächlich an der Wandung des Glases anhaften oder gleichmässig in der Flüssigkeit suspendirt sein. Alle diese Differęnzen beruhen natürlich auf rein physikalischen Gründen, es mögen dabei das 
specifische Gewicht der Bakterien, die Beschaffenheit der Oberfläche, in gewissem Grade auch die Figenschaften der Zwischenflüssigkeit in Betracht kommen; etwas Nāheres ist uns darüber nicht bekannt. Daher können wir natürlich auch vorläufig keine specielle Vermuthung darüber aussprechen, welcher Art die Veränderungen sind, die eben diese physikalischen Eigenschaften der Bakterienzelle unter dem Einflusse des in die Zelle eindringenden Agglutinins erleiden; dass jedoch eine solche tiefgreifende Aenderung 'stattfindet, lässt sich deutlich erkennen. So nimmt unter diesem Einflusse z. B. der Pneumococcus ähnliche Eigenschaften an, wie sie ein Streptococcus longus von vornherein besitzt; daher ist nunmehr sein "Gleichgewichtszustand" ein ähnlicher wie bei diesem, und ein ganz anderer als der einer normalen Pneumokokkencultur.

Die von mir vertretene Ansicht über das Wesen der Agglutination schliesst sich, wie man sieht, in den wesentlichen Punkten der von Bordet ${ }^{1}$ aufgestellten Theorie an. Bordet unterschied zuerst zwei Stadien des Agglutinationsphänomens, das erste der Fixirung des Agglutinins durch die noch getrennten Mikroorganismen, das zweite der eigentlichen Haufenbildung. Er zeigte, dass man das erste Stadium isolirt zur Anschautung bringen kann, nämlich in einem salzfreien Medium, wo die Mikroben das Agglutinin $\mathrm{zwar}$ an sich reissen, aber getrennt bleiben. Bordet nimmt an, ;,dass die Agglutinine dadurch, dass sie sich an den agglutinirbaren Elementen fixiren, Modificationen in der molekularen Anziehung herbeiführen, welche diese Elemente sowohl unter sich, als mit der umgebenden Flüssigkeit verbindet". Er findet den engsten Zusammenhang zwischen den Vorgängen der Agglutination und der Codgulation (Präcipitation). Wie bei der Agglatination die Bakterien, so treten bei der Präcipitation specifisch beeinflusste Molekulargruppen zu einem Niederschlage zu einander, während sie vorher so von einander getrennt und fein vertheilt waren, dass die Flüssigkeit ganz klar ersehien. In beiden Fällen handelt es sich um ein ,phénomène de rapprochement des particules sous l'influence d'un changement dans les relations d'attraction moléculaire".

\section{Die Immunisirung gegen Pneumokokken.}

Die im Vorstehenden berichteteten Beobachtungen über die Agglutination der Pneumokokken machte ich zuerst im Sommer 1899 an einigen Blutproben von Patienten, welche eine typische Pneumonie überstanden

${ }^{1}$ Le mécanisme de l’agglutination. Annales de l'Institut Pasteur. 1899. 
hatten, sodann setzte ich sie an einer grösseren Anzahl von Thieren fort, die in verschiedener Weise und in verschieden hohem Grade gegen die Fränkel'schen Diplokokken immunisirt waren. Auf meine sonstigen Beobachtungen gelegentlich dieser Immunisirungen und auf die immanisirende Wirkung des dabei erbaltenen Serums werde ich alsbald in einer weiteren Arbeit zurückkommen, wobei dann auch die bisherige litteratur über die Immunităt bei Pneumokokken gewürdigt werden soll. Hier will ich nur eine vorläufige Mittheilung machen über die wesentlichen Punkte der Pneumokokkenimmunisirung, sowie hinzufügen, in welcher Weise dieselbe zu modificiren ist, wenn es sich speciell um Gewinnung stark agglutinirenden Serums handelt.

Das Grundprincip meiner Methode, Thiere schnell und ohne Verluste hoch zu immunisiren, bildet die: möglichst ausschliessliche Benutzung der Bakterienkörper - zuerst der abgetödteten, dann der lebenden -, welche man durch Ausschleudern frischer Bouillonculturen mittels einer schnell laufenden Centrifuge erhält. Die im Filtrate einer jungen Bouilloncultur vorhandenen, also wohl durch Secretion entstandenen Giftstoffe, die allerdings überhaupt von ziemlich schwacher Wirkung sind, sind zur Immunisirung nicht nur völlig entbehrlich, sondern gelegentlich sogar hinderlich; dazu kommt, dass bei grösseren Bouillonmengen, zu denen man schnell aufsteigt, auch die in der Bouillon enthaltenen Stoffe für die Thiere nicht indifferent sind. So kommt man bei Benutzung der ganzen Bouilloncultur bald an eine Grenze, wo die Thiere nicht durch die Virulenz der lebenden Keime, sondern durch Giftwirkung eingehen.

Die abgetödteten Bakterienkörper halhen dagegen auch in grossen Dosen keine sichtlich krankmachende, dafür aber eine sichere immunisirende Wirkung und zwar lässt sich ein relativ hoher Grad von Immunität auf diese Weise erreichen. Hat man einen hochvirulenten Coccus, der in der Dosis von 0.000001 Kaninchen tödtet, so kann man durch eine einzige genügende Dosis abgetödteter Bakterien ein Thier leicht gegen 0.1 der lebenden Cultur schützen. Es ist nicht rationell, mehr als eine Dosis des abgetödteten Materials zu injiciren, sondern sofort zu der lebenden Cultur überzugehen. Nit dieser muss beträchtlich schneller gestiegen werden, als man es bei anderen Immunisirungen gewohnt ist, jedes Mal etwa auf das Zwei- bis Fünffiache und darüber, Anfangs schneller, später langsamer. Auf diese Weise lassen sich Kaninchen, Meerschweinchen, Hunde, Ziegen leicht $z u$ hohen Dosen bringen. So vertragen z. B. Kaninchen alsbald die in $100^{\mathrm{cm}}$ Bouilloncultur enthaltenen lebenden und hochvirulenten Pneumobokken.

Wenn man in der beschriebenen Weise vorgeht, so kann man zwar mit Sicherheit die Versuchsthiere schnell gegen sehr hohe Dosen des riru- 
lentesten Materials immunisiren, dabei wird man aber nur ausnahmsweise ein Serum erhalten, an welchem man die beschriebenen Agglutinationsvorgänge studiren kann. Nur jenen ganz schwachen Gehalt von Agglutinin wird solcher Serum häufig besitzen, der gerade genügt, um in unverdünntem Zustande nach 24 Stunden die schon lange bekannten Erscheinungen des agglutinirten Wachsthums an einer eingesäten Cultur hervorzurufen. Das Auftreten eines starken Agglutiningehaltes ist nämlich durchaus unabhängig von der Höhe der Immunität, welche das betreffende Thier besitzt und allein von der letzten Reaction, die es durchgemacht hat. Ein Beispiel möge das erläutern.

Ein Kaninchen erbält am 26. VIII. 1899 eine rorbereitende Injection

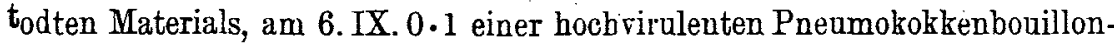
cultur subcutan; darauf zeigte das am 13. IX. entnommene Serum kräftige Agglutination (bis $1: 30$ ). Das Thier wurde weiter immunisirt, und vertrug schliesslich mehr als das tausendfache der ersten Dosis lebender Cultur. Sein Blut hatte aber seine Agglutinationsfähigkeit inzwischen völlig verloren. Derartige Beobachtungen habe ich oft gemacht, und gut agglutinirendes Serum in der Regel nicht bei hochimmunisirten Thieren erhalten, sondern nur dann, wenn angenscheinlich die letzte Dosis nicht weit unterhalb der tödtlichen gelegen hatte. Oefter bin ich zu diesem Zwecke gleich auf das 10 fache der vorigen Dosis gestiegen, in anderen Fällen habe ich mehrmals hinter einander in Zwischenräumen von 1 bis 2 Tagen steigende Mengen intravenös gegeben. Hierfür mögen die folgenden beiden Protocolls als Beispiele dienen.

1. Ein Kaninchen erhält am 10.X.1900 von dem Serum eines anderen, mässig hoch immunisirten Kaninchens $1.0^{\mathrm{ccm}}$ intravenös.

11.X. $0.1^{\mathrm{cm}}$ Pneumokokkenbouilloncultur, subcutan. (Controlthier mit 0.00001 . $\dagger$ am 3. Tage.)

20.X. $0.1^{\mathrm{cem}}$ intravenös. 6. XI. Schwache Agglutination des Serums.

6. XI. $0.8^{\mathrm{ccm}}$ intravenös. 13.XI. Serum agglutinirt stark.

Bei weiterer Immunisirung schwächt sich das Agglutinationsvermögen des Serums ab.

2. Ein zweites Kaninchen erhält am

11. X. $1.0 \mathrm{ccm}$ Immunserum intravenös. 3 Stunden darauf:

11. X. 0.1, hochvirulenter Cultur, subcutan.

20. X. $0.1 \%$ derselben Cultur intravenös: keine Agglutination.

6. XI. $0.4 " \quad " \quad "$

9.XI. $2 \cdot 0 " \quad " \quad "$

12.XI. $4.0, ", "$,

Am 19.XI. Blutentnahme: stark agglutinirendes Serum.

Dass man bei solchem Vorgehen leicht Verluste hat, liegt auf der Hand. 
Auf die einfachste Weise kann man aber ziemlich gut agglutinirendes Serum von nicht vorbehandelten Kaninchen durch Impfung mit solchen Culturen gewinnen, welche von Anfang an nur mittlere Virulenz besitzen. Injicirt man davon solche Dosen, welche die Thiere schwer krank machen, aber nicht tödten, so wird man, besonders wenn man mehrere Thiere gleichzeitig in Versuch nimmt, leicht eins darunter finden, welches geeignetes Serum liefert. Bei subcutaner Impfung am Ohre bietet die locale Erkrankung einen einfachen Maassstab zur Beurtheilung der Reaction. Die geeignete Zeit zur Blutprüfung ist die vom 8. bis 12. Tage; bei langsam verlaufender Erkrankung muss man jedoch noch länger warten.

Da hiernach Thiere, welche eine von einem mässig virulenten Erreger ausgelöste Erkrankung in Folge ihrer natürlichen Widerstandsfâhigkeit überwunden haben, in ihrem Blute dieselben specifischen Stoffe bilden können, wie solche, die künstlich gegen vollvirulente Keime immunisirt sind, so ist von vornherein wahrseheinlich, dass wir dieselben bei Stoffe auch Menschen, die eine natürliche Erkrankung durchgemacht haben, finden werden. In der That habe ich bei fünf Pneumoniereconvalescenten, welche eine schwere, typische Erkrankung mit ausgesprochener Krisis überstanden hatten, ein Serum erhalten, welches die beschriebenen Erscheinungen einer schnellen Agglutination in deutlichster Weise erkennen liess. Entsprechend den Beobachtungen an Thieren tritt auch beim Menschen durchaus nicht in jedem Falle von Pneumonie ein derart wirksames Serum auf; nach meinem, leider sehr spärlichen Material möchte ich annehmen; dass es etwa nur in jedem dritten oder vierten Falle zu erwarten sei. Hierbei ist immer nur die Rede von der eigentlichen Agglutination; ein ,agglutinirtes Wachsthum" dagegen lässt sich in stärkerem oder schwächerem Grade in den meisten, freilich auch nicht in allen Fällen bei den Reconvalescenten von Pneumonie beobachten; wenigstens habe ich es in einem typischen Falle vermisst. Im Uebrigen sei in dieser Beziehung auf die schon erwähnten Beobachtungen von Besançon und Griffon verwiesen. Gelegentlich wird auch der Kliniker von dieser Reaetion Gebrauch machen können; allzuviel praktischen Nutzen möchte ich, wie schon gesagt, davon nicht erwarten.

Das Agglutinationsvermögen fand ich stets am Tage nach der Krisis voll ausgebildet, während es zu Beginn der Eirkrankung fehlte; 8 Tage nach der Krisis fand ich es noch annähernd auf derselben Höhe. Dass bisweilen die agglutinirenden Stoffe im Serum schon einige Zeit vor der Krisis reichlich angehäuft sein können, beweist folgende an einer Patientin in der Krankenabtheilung des Instituts gemachte Beobachtung. Es handelte sich um eine schwere Pneumonie, bei welcher ein ungünstiger Ausgang zu erwarten schien.' Es wurde daher zu therapeutischem Zweck ein 
reichlicher Aderlass gemacht. Erst 36 Stunden nach demselben trat die Krisis ein. Das Aderlassblut zeigte starke Agglutination, ungefähr ebenso starke, als eine nach der Krisis entnommene Blutprobe. Die Deutung dieses Befundes kann nach unseren jetzigen Kenntnissen über die Immunitātsvorgänge wohl nicht zweifelhaft sein. Wir werden uns wegen dieses auf der Höhe der Krankheit gefundenen Agglutinationsvermögens gewiss nicht der von einigen französischen Autoren vertheidigten Anschauung anschliessen, die Agglutination sei eine "Infectionsreaction" aber nicht eine Begleiterscheinung der Immunisirung. Nach allem, was wir über die Entstehung des Agglutinins wissen, ist es sicher, dass dasselbe ebenso gut wie die immunisirenden Substanzen des Blutes ein Reactionsproduct des Körpers gegen eindringende Mikroorganismen darstellt; auch pflegen beide Arten von Stoffen in den meisten Fällen ungefähr gleichzeitig aufzutreten. Dies war auch in dem erwähnten Krankheitsfalle der Fall: das 36 Stunden vor der Krisis gewonnene Blut hatte neben seiner agglutinirenden Eigenschaft auch einen hohen Immunisirungswerth. Gerade bei einer mit so typischer Krise endigenden Krankheit, wie es die Pneumonie ist, scheint mir der Nachweis von Interesse, dass schon längere Zeit, bevor der plötzliche Omschlag im Befinden des Kranken eintritt, grosse Mengen immunisirender Substanzen im Blute angehäuft sein können. 